\section{Advance care planning and end-of- life care preferences in community- dwelling Hong Kong Chinese elders with medical problems and their next of kin: a cross-sectional study}

\author{
Mei-Ling Tsang, FHKCP, FHKAM, KM Yeung ${ }^{1}$, FHKCP, FHKAM, Kenny WM \\ Wong' ${ }^{2}$ FHKCP, FHKAM, PT Lam ${ }^{3}$, FHKCP, FHKAM, KY Lam ${ }^{4}$, FHKCP, FHKAM, \\ CY Lam $^{5}$, FHKCP, FHKAM, Christopher CM Lum ${ }^{6}$ FHKCP, FHKAM
}

\begin{abstract}
Objectives. The present study aimed to determine advance care planning and end-of-life care preferences of community-dwelling Hong Kong elders with medical problems and their next of kin, and to determine the predictors of their preferences.

Methods. Community-dwelling Chinese aged $\geq 65$ years who attended one of the six medical and geriatric out-patient clinics or geriatric day hospitals between July 2012 and August 2013 were included, as were their next of kin. Interview was conducted based on a structured questionnaire. Socio-demographic data, comorbidities, functional status measured by the Katz score, self-perceived health status, and life satisfaction were collected. Preferences for end-of-life care and advance care planning were explored using hypothetical scenarios of an advanced illness. Associations between end-of-life care preferences and other variables were determined. Preferences for end-of-life care were compared between the elders and their next of kin.
\end{abstract}

Results. A total of 153 female and 114 male elders (mean age, 79.2 years) and a total of 128 female and 74 male next of kin were included. Respectively for the elders and next of kin, $87.6 \%$ and $88.1 \%$ agreed to let 'nature to guide the elder life'; $83.5 \%$ and $97 \%$ preferred adequate pain control to keep them 'free of pain' despite the side-effect of drowsiness; $65.5 \%$ and $43.6 \%$ preferred not to use cardiopulmonary resuscitation; $64.8 \%$ and $45.1 \%$ preferred not to use intubation; $74.9 \%$ and $53.9 \%$ preferred not to use nasogastric tube feeding; $43.5 \%$ and $59.4 \%$ preferred'repeated courses of antibiotics for infection despite no improvement noted'; $91.6 \%$ and $87.9 \%$ preferred small oral feeding (rather than the use of nasogastric tube); and $75.5 \%$ and $65.6 \%$ preferred oral medications (rather than non-invasive positive pressure ventilation). For advance care planning, respectively for the elders and next of kin, $58.4 \%$ and $71.4 \%$ preferred the doctor to discuss advance care planning with both the patient and family members; $7.9 \%$ and $15.1 \%$ preferred the doctor to discuss with family members only; $21.7 \%$ and $7.0 \%$ preferred the doctor to discuss with the patient only; and $11.6 \%$ and $6.5 \%$ preferred to let the doctor to make decisions. There were significant discordance between elders and next of kin in terms of treatment preference in case of short of breath $(\mathrm{p}=0.004)$ and all end-of-life care preferences, except for'let nature guide one's life'.

Conclusions. There was significant discordance in end-of-life care preferences between elders and their next of kin. In order to deliver end-oflife care in accordance with elder's values and beliefs, advance care planning should be discussed with them before they become too ill to do so.

Key words: Advance care planning; Aged; Family; Terminal care

\section{ORIGINAL ARTICLE}

Medical and Geriatric Department, Princess Margaret Hospital, Hong Kong Medical and Geriatric Department, Tuen Mun Hospital, Hong Kong

Medical and Geriatric Department, United Christian Hospital, Hong Kong

4 Medical and Geriatric Department, Kwong Wah Hospital, Hong Kong

5 Medical Department, Queen Elizabeth Hospital, Hong Kong

Medical and Geriatric Department, Shatin Hospital, Hong Kong 


\section{INTRODUCTION}

A pop song by Lana Del Rey 'We were born to die' highlights two healthcare processes that are relevant to all people: being born and dying. Conventional medical teaching is to prolong life so dying may be viewed as an undesirable outcome or a failure. Nonetheless, death is inevitable despite medical advancements.

In end-of-life care, five important domains have been identified: symptom control, ongoing assessment of quality of life, alleviating burden, strengthening relationships, and discussions about the end-of-life decision-making process. ${ }^{1,2}$ Advance care planning is a process that allows patients to express their preferences for end-of-life care, and enables their next of kin and healthcare workers to understand their preferences and to make decisions on the patient's behalf when the patient is unable to do so. ${ }^{3}$ In an observational cohort study, advance care planning was associated with improved quality of care at the end-of-life. ${ }^{4}$ In a randomised controlled trial, advance care planning improved end-of-life care as well as patient and family satisfaction, and reduced stress, anxiety, and depression in surviving relatives. ${ }^{3}$ In a cross-sectional study, patients with chronic obstructive pulmonary disease (COPD) who had an end-of-life care discussion with physicians had higher perceived quality of care and satisfaction with the care received. ${ }^{5}$ In a systematic review, advance care planning demonstrated a positive impact on quality of end-of-life care in terms of increased frequency of out of hospital and out of intensive care unit care, increased compliance with patient end-of-life wishes and satisfaction with care, and absence of adverse effects of advance care planning on psychosocial outcomes. ${ }^{6}$

In Hong Kong, there is a growing interest in endof life care for terminally ill older adults. Nevertheless, only a few studies have reported end-of-life preferences among Chinese; most such studies have been conducted among elders in nursing homes. ${ }^{7-9}$ One study presented a hypothetical condition of either a terminal illness or a persistent vegetative state / irreversible coma to 1600 cognitively intact elders in nursing homes. ${ }^{9}$ Another study reported the attitudes of Hong Kong Chinese elders with chronic disease on life-sustaining treatment in a medical unit of a teaching hospital. Of 219 elders who completed the interview, 209 were community living. ${ }^{10}$ One study reported end-of-life decision preferences of older Macau Chinese using a quality approach via semi-structured questions. ${ }^{11}$ The present study aimed to determine advance care planning and end-of-life care preferences of community-dwelling Hong Kong elders with medical problems and their next of kin, and to determine the predictors of their preferences.

\section{METHODS}

This cross-sectional study was approved by the Hospital Authority Kowloon Central / Kowloon East Cluster Research Ethics Committee, Kowloon West Cluster Research Ethics Committee, and New Territories West Cluster Research Ethics Committee. Community-dwelling Chinese aged $\geq 65$ years who attended one of the six medical and geriatric outpatient clinics or geriatric day hospitals between July 2012 and August 2013 were included, as were their next of kin. Elders were excluded if they were living in a residential or care home, were nonChinese, unable to communicate in Cantonese, diagnosed with dementia, refused consent, or had no contactable next of kin. Interview based on a structured questionnaire was conducted face-to-face for patients and in person or by phone for next of kin.

Socio-demographic data, comorbidities, functional status measured by the Katz score, ${ }^{12,13}$ self-perceived health status, and life satisfaction were collected. Preferences for end-of-life care and advance care planning were explored using hypothetical scenarios of an advanced illness. Scenario exposure has been shown to significantly improve the knowledge level of participants. ${ }^{14}$ Outcome measures included preferences for advance care planning and end-of-life care, and predictors of these preferences.

Associations between end-of-life care preferences and socio-demographic variables, total hospital stay in the past year, total Katz score, self-perceived health status, life satisfaction, or chronic diseases were determined using the Chi-square test or independent $t$-test. Preferences for end-of-life care were compared between the elders and their next of kin using the McNemar test. A p value of $<0.05$ was considered statistically significant. 


\section{RESULTS}

A total of 153 female and 114 male elders (mean age, 79.2 years) were included (TABLE 1). The five most common comorbidities were hypertension $(57.3 \%)$, cerebrovascular accident $(43.1 \%)$, diabetes mellitus $(28.5 \%)$, congestive heart failure $(15.4 \%)$, and ischaemic heart disease (14.6\%). The mean Katz score for functional status was 4.72. A total of 128 female and 74 male next of kin were included; most were in the age-group of 40 to $<60$ years $(55 \%)$ or 60 to $<80$ years $(28 \%)$, and were a child $(63.7 \%)$ or spouse $(29.4 \%)$ of the elder.

In a hypothetical scenario of an acute lifethreatening condition secondary to a terminal disease or advanced illness, preferences for end-oflife care were determined (TABLE 2). Respectively for the elders and next of kin, $87.6 \%$ and $88.1 \%$ agreed to let'nature to guide the elder life'; $83.5 \%$ and $97 \%$ preferred adequate pain control to keep them 'free of pain' despite the side-effect of drowsiness; $65.5 \%$ and $43.6 \%$ preferred not to use cardiopulmonary resuscitation (CPR); $64.8 \%$ and $45.1 \%$ preferred not to use intubation; $74.9 \%$ and $53.9 \%$ preferred not to use nasogastric tube feeding; and $43.5 \%$ and $59.4 \%$ preferred 'repeated courses of antibiotics for infection despite no improvement noted'.

In a hypothetical scenario where the elder had advanced dementia and needed major assistance in self-care and could not verbally communicate and ate very little, respectively for the elders and next of kin, $91.6 \%$ and $87.9 \%$ preferred small oral feeding (rather than the use of nasogastric tube), even if the amount was insufficient to maintain nutrition and health. In a hypothetical scenario where the elder had chronic lung disease and shortness of breath, respectively for the elders and next of kin, $75.5 \%$ and $65.6 \%$ preferred oral medications (rather than noninvasive positive pressure ventilation) despite the side-effect of drowsiness (TABLE 3).

In a hypothetical scenario where the elder had an advanced disease but was not acutely ill, respectively for the elders and next of kin, $58.4 \%$ and $71.4 \%$ preferred the doctor to discuss advance care planning with both the patient and family members; $7.9 \%$ and $15.1 \%$ preferred the doctor to discuss with family members only; $21.7 \%$ and $7.0 \%$ preferred the doctor to discuss with the patient only; and $11.6 \%$
TABLE 1

Socio-demographics of elders and next of kin

\begin{tabular}{|c|c|c|}
\hline Characteristic & $\begin{array}{c}\text { Elders } \\
(\mathrm{n}=267)^{\star}\end{array}$ & $\begin{array}{l}\text { Next of kin } \\
(n=202)^{\star}\end{array}$ \\
\hline \multicolumn{3}{|l|}{ Sex } \\
\hline Male & $114(42.7)$ & $74(36.6)$ \\
\hline Female & $153(57.3)$ & $128(63.4)$ \\
\hline Age, y & $79.2 \pm 7.51$ & - \\
\hline Age group, y & & $n=200$ \\
\hline$<40$ & - & $19(9.5)$ \\
\hline 40 to $<60$ & - & $110(55)$ \\
\hline 60 to $<80$ & - & $56(28)$ \\
\hline$\geq 80$ & - & $15(7.5)$ \\
\hline \multicolumn{3}{|l|}{ Presentation setting } \\
\hline Geriatric day hospital & $182(68.2)$ & - \\
\hline Out-patient clinic & $85(31.8)$ & - \\
\hline Relationship & & $n=201$ \\
\hline Child & - & $128(63.7)$ \\
\hline Spouse & - & $59(29.4)$ \\
\hline In-law & - & $8(4.0)$ \\
\hline Other & - & $6(3.0)$ \\
\hline Education & $n=264$ & $n=199$ \\
\hline Nil & $97(36.7)$ & $10(5.0)$ \\
\hline Primary & $107(40.5)$ & $45(22.6)$ \\
\hline Secondary & 48 (18.2) & $110(55.3)$ \\
\hline Tertiary & $12(4.5)$ & $34(17.1)$ \\
\hline $\begin{array}{l}\text { Self-rated health status compared } \\
\text { with peers }\end{array}$ & $n=267$ & - \\
\hline Worse & $74(27.7)$ & - \\
\hline Same & $121(45.3)$ & - \\
\hline Better & $72(27.0)$ & - \\
\hline Comorbidities & $n=267$ & - \\
\hline Hypertension & $153(57.3)$ & - \\
\hline Cerebrovascular accident & $115(43.1)$ & - \\
\hline Diabetes mellitus & $76(28.5)$ & - \\
\hline Congestive heart failure & $41(15.4)$ & - \\
\hline Ischaemic heart disease & $39(14.6)$ & - \\
\hline Chronic renal failure & $30(11.2)$ & - \\
\hline $\begin{array}{l}\text { Chronic obstructive pulmonary } \\
\text { disease }\end{array}$ & $29(10.9)$ & - \\
\hline Cognitive impairment & $20(7.5)$ & - \\
\hline Katz Score $(n=244)$ & $4.72 \pm 1.57$ & - \\
\hline $\begin{array}{l}\text { No. of acute admissions in past } \\
\text { year }(n=267)\end{array}$ & $1.66 \pm 1.96$ & - \\
\hline $\begin{array}{l}\text { No. of non-acute admissions in } \\
\text { past year }(n=267)\end{array}$ & $0.77 \pm 1.77$ & - \\
\hline $\begin{array}{l}\text { Self-rated life satisfaction, visual } \\
\text { analogue scale }(n=267)\end{array}$ & $6.71 \pm 2.32$ & - \\
\hline $\begin{array}{l}\text { Total hospital stay in past year, } d \\
(n=267)\end{array}$ & $22.8 \pm 25.1$ & - \\
\hline
\end{tabular}

* Data are presented as No. (\%) or mean \pm standard deviation 
and $6.5 \%$ preferred to let the doctor make decisions (TABLE 4).

The four possible responses for end-of-life care preferences were dichotomised into 'agree' and 'disagree' for bivariate analysis to determine predictors for end-of-life care preferences in the elders (TABLE 5). Older age was the predictor for the preference of not to use CPR $(\mathrm{p}=0.01)$. Lower
Katz score was the predictor for the preference for repeated courses of antibiotic $(\mathrm{p}=0.043)$. Higher number of comorbidities was the predictor for the preference for repeated courses of antibiotic $(p=0.045)$. Higher number of acute admissions in the past year was the predictor for the preference against not to use CPR ( $\mathrm{p}=0.039)$ and not to use nasogastric tube feeding $(\mathrm{p}=0.006)$ as well as the preference against 'nature to guide one's life' $(\mathrm{p}=0.001)$. Higher

TABLE 2

End-of-life care preferences in elders and next of kin

\begin{tabular}{|c|c|c|c|c|c|c|c|c|c|c|}
\hline \multirow[t]{2}{*}{ End-of-life care } & \multicolumn{5}{|c|}{ No. $(\%)$ of elders } & \multicolumn{5}{|c|}{ No. (\%) of next of kin } \\
\hline & $\begin{array}{l}\text { Strongly } \\
\text { disagree }\end{array}$ & Disagree & Agree & $\begin{array}{l}\text { Strongly } \\
\text { Agree }\end{array}$ & Uncertain & $\begin{array}{l}\text { Strongly } \\
\text { disagree }\end{array}$ & Disagree & Agree & $\begin{array}{c}\text { Strongly } \\
\text { Agree }\end{array}$ & Uncertain \\
\hline Let nature guide one's life & $16(6.0)$ & $16(6.0)$ & $112(41.9)$ & $122(45.7)$ & $1(0.4)$ & $6(3.0)$ & $17(8.4)$ & $121(59.9)$ & $57(28.2)$ & $1(0.5)$ \\
\hline $\begin{array}{l}\text { Adequate pain control } \\
\text { despite side-effect of } \\
\text { drowsiness }\end{array}$ & $13(4.9)$ & $31(11.6)$ & $114(42.7)$ & $109(40.8)$ & $0(0)$ & $1(0.5)$ & $5(2.5)$ & $125(61.9)$ & $71(35.1)$ & $0(0)$ \\
\hline $\begin{array}{l}\text { Not to use cardiopulmonary } \\
\text { resuscitation }\end{array}$ & $23(8.6)$ & $66(24.7)$ & $74(27.7)$ & $101(37.8)$ & $3(1.1)$ & $23(11.4)$ & $89(44.1)$ & $49(24.3)$ & $39(19.3)$ & $2(1.0)$ \\
\hline Not to use intubation & $23(8.6)$ & $68(25.5)$ & $82(30.7)$ & $91(34.1)$ & $3(1.1)$ & $21(10.4)$ & $85(42.1)$ & $62(30.7)$ & $29(14.4)$ & $5(2.5)$ \\
\hline Not to use nasogastric tube & $21(7.9)$ & $42(15.7)$ & $99(37.1)$ & $101(37.8)$ & $4(1.5)$ & $16(7.9)$ & $70(34.7)$ & $75(37.1)$ & $34(16.8)$ & $7(3.5)$ \\
\hline $\begin{array}{l}\text { Repeated courses of } \\
\text { antibiotics for infection } \\
\text { despite no improvement } \\
\text { noted }\end{array}$ & $59(22.1)$ & 87 (32.6) & $84(31.5)$ & $32(12.0)$ & $5(1.9)$ & $15(7.4)$ & $60(29.7)$ & $98(48.5)$ & $22(10.9)$ & 7 (3.5) \\
\hline
\end{tabular}

TABLE 3

Feeding and treatment preferences of elders and next of kin

\begin{tabular}{lcc}
\hline Preference & No. (\%) of elders & No. (\%) of next of kin \\
\hline Feeding preference in advanced dementia & $\mathrm{n}=263$ & $\mathrm{n}=199$ \\
Nasogastric tube & $22(8.4)$ & $24(12.1)$ \\
Small oral feeding & $241(91.6)$ & $175(87.9)$ \\
Treatment preference in shortness of breath & $\mathrm{n}=265$ & $\mathrm{n}=195$ \\
Non-invasive positive pressure ventilation & $65(24.5)$ & $67(34.4)$ \\
Oral medications & $200(75.5)$ & $128(65.6)$ \\
\hline
\end{tabular}

TABLE 4

Advance care planning of elders and next of kin

\begin{tabular}{lcc}
\hline Advance care planning & No. $(\%)$ of elders $(\mathrm{n}=226)$ & No. $(\%)$ of next of kin $(\mathrm{n}=199)$ \\
\hline Doctor to discuss with both patient and family & $156(58.4)$ & $142(71.4)$ \\
Doctor to discuss with patient only & $58(21.7)$ & $14(7.0)$ \\
Doctor to discuss with family only & $21(7.9)$ & $13(15.1)$ \\
Doctor to make decision (no need to discuss) & $31(11.6)$ & $13(6.5)$ \\
\hline
\end{tabular}


TABLE 5

Predictors of end-of-life care preferences

\begin{tabular}{|c|c|c|c|c|c|c|}
\hline \multirow[t]{2}{*}{ Variable } & \multicolumn{6}{|c|}{ End-of-life care preference } \\
\hline & $\begin{array}{l}\text { Let nature } \\
\text { guide one's } \\
\text { life }\end{array}$ & $\begin{array}{l}\text { Adequate } \\
\text { pain control } \\
\text { despite } \\
\text { side-effect of } \\
\text { drowsiness }\end{array}$ & $\begin{array}{l}\text { Not to use } \\
\text { cardiopulmonary } \\
\text { resuscitation }\end{array}$ & $\begin{array}{l}\text { Not to use } \\
\text { intubation }\end{array}$ & $\begin{array}{c}\text { Not to use } \\
\text { nasogastric } \\
\text { tube }\end{array}$ & $\begin{array}{c}\text { Repeated courses } \\
\text { of antibiotics for } \\
\text { infection despite } \\
\text { no improvement } \\
\text { noted }\end{array}$ \\
\hline & \multicolumn{6}{|c|}{$\mathrm{p}$ Value (Chi square test) } \\
\hline Sex & 0.85 & 0.24 & 0.051 & 0.09 & 0.57 & 0.21 \\
\hline Presentation setting & 0.45 & 0.48 & 0.41 & 0.22 & 0.36 & 0.09 \\
\hline Education & 0.94 & 0.86 & 0.29 & 0.20 & 0.58 & 0.95 \\
\hline \multirow[t]{2}{*}{ Self-rated life satisfaction } & 0.43 & 0.79 & 0.89 & 0.48 & 0.52 & 0.77 \\
\hline & \multicolumn{6}{|c|}{ Mean \pm standard deviation (independent $t$-test) } \\
\hline \multicolumn{7}{|l|}{ Age, y } \\
\hline Disagree & $80.3 \pm 7.67$ & $78.7 \pm 6.51$ & $77.6 \pm 7.47$ & $78 \pm 7.69$ & $78 \pm 7.89$ & $79.7 \pm 7.34$ \\
\hline Agree & $79.0 \pm 7.49$ & $79.3 \pm 7.7$ & $80.1 \pm 7.40$ & $79.8 \pm 7.34$ & $79.6 \pm 7.35$ & $78.6 \pm 7.69$ \\
\hline$p$ Value & 0.37 & 0.63 & 0.01 & 0.059 & 0.15 & 0.25 \\
\hline \multicolumn{7}{|l|}{ Katz score } \\
\hline Disagree & $4.41 \pm 1.57$ & $4.81 \pm 1.62$ & $4.57 \pm 1.71$ & $4.54 \pm 1.56$ & $4.68 \pm 1.76$ & $4.91 \pm 1.37$ \\
\hline Agree & $4.76 \pm 1.57$ & $4.7 \pm 1.56$ & $4.79 \pm 1.50$ & $4.81 \pm 1.58$ & $4.73 \pm 1.51$ & $4.50 \pm 1.75$ \\
\hline $\mathrm{p}$ Value & 0.27 & 0.68 & 0.28 & 0.21 & 0.83 & 0.043 \\
\hline \multicolumn{7}{|l|}{ No. of comorbidities } \\
\hline Disagree & $1.91 \pm 1.26$ & $2.05 \pm 1.2$ & $1.98 \pm 1.33$ & $1.99 \pm 1.32$ & $1.82 \pm 1.24$ & $1.75 \pm 1.23$ \\
\hline Agree & $1.88 \pm 1.20$ & $1.86 \pm 1.2$ & $1.84 \pm 1.13$ & $1.83 \pm 1.14$ & $1.9 \pm 1.2$ & $2.05 \pm 1.15$ \\
\hline$p$ Value & 0.91 & 0.34 & 0.38 & 0.31 & 0.78 & 0.045 \\
\hline \multicolumn{7}{|c|}{ No. of acute admissions in past year } \\
\hline Disagree & $2.67 \pm 2.89$ & $1.42 \pm 1.18$ & $2.00 \pm 2.03$ & $1.89 \pm 1.87$ & $2.23 \pm 2.35$ & $1.64 \pm 2.03$ \\
\hline Agree & $1.51 \pm 1.75$ & $1.70 \pm 2.08$ & $1.48 \pm 1.90$ & $1.53 \pm 2$ & $1.47 \pm 1.78$ & $1.68 \pm 1.88$ \\
\hline p Value & 0.001 & 0.38 & 0.039 & 0.15 & 0.006 & 0.86 \\
\hline \multicolumn{7}{|c|}{ No. of non-acute admissions in past year } \\
\hline Disagree & $1.61 \pm 3.05$ & $0.35 \pm 0.65$ & $0.98 \pm 1.85$ & $0.84 \pm 1.64$ & $1.21 \pm 2.29$ & $0.81 \pm 1.89$ \\
\hline Agree & $0.65 \pm 1.48$ & $0.85 \pm 1.91$ & $0.66 \pm 1.73$ & $0.74 \pm 1.85$ & $0.62 \pm 1.54$ & $0.73 \pm 1.62$ \\
\hline$p$ Value & 0.004 & 0.09 & 0.17 & 0.65 & 0.02 & 0.74 \\
\hline \multicolumn{7}{|c|}{ Total hospital stay in past year, d } \\
\hline Disagree & $20.6 \pm 1.57$ & $22.4 \pm 21.8$ & $24.4 \pm 2.55$ & $25.2 \pm 23.9$ & $26.4 \pm 27.2$ & $22.9 \pm 25.7$ \\
\hline Agree & $23.1 \pm 25.4$ & $22.9 \pm 25.8$ & $22.0 \pm 25.6$ & $21.5 \pm 25.8$ & $21.6 \pm 24.3$ & $22.7 \pm 24.5$ \\
\hline p Value & 0.59 & 0.91 & 0.46 & 0.26 & 0.18 & 0.96 \\
\hline
\end{tabular}

number of non-acute admissions was the predictor for the preference against not to use nasogastric tube feeding ( $\mathrm{p}=0.02)$ as well as the preference against 'nature to guide one's life' $(\mathrm{p}=0.004)$.

Discordance in preferences for end-of-life care between the elders and next of kin was determined using the McNemar test (TABle 6). Concordance between the elders and next of kin was high in terms of 'let nature guide one's life' (81.2\%), 'adequate pain control despite side-effect of drowsiness' (83.2\%), and 'feeding preference in advanced dementia' $(82 \%)$. Concordance between the elders and next of kin was low in terms of use of CPR (54.5\%), 
TABLE 6

Discordance in end-of-life care preferences between elders and next of kin

\begin{tabular}{|c|c|c|c|c|}
\hline \multirow[t]{3}{*}{ End-of-life care preference } & \multicolumn{3}{|c|}{ No. $(\%)$ of paired samples $(n=202)$} & \multirow[t]{3}{*}{ p Value } \\
\hline & \multirow[t]{2}{*}{ Concordance } & \multicolumn{2}{|c|}{ Discordance } & \\
\hline & & $\begin{array}{l}\text { Disagree (elder) - agree } \\
\text { (next of kin) }\end{array}$ & $\begin{array}{l}\text { Agree (elder) - disagree } \\
\text { (next of kin) }\end{array}$ & \\
\hline Let nature guide one's life & $164(81.2)$ & $19(9.41)$ & $19(9.41)$ & 1.0 \\
\hline $\begin{array}{l}\text { Adequate pain control despite side-effect of } \\
\text { drowsiness }\end{array}$ & $168(83.2)$ & $30(14.8)$ & $4(1.98)$ & $<0.001$ \\
\hline Not to use cardiopulmonary resuscitation & $110(54.5)$ & $24(11.9)$ & $68(33.7)$ & $<0.001$ \\
\hline Not to use intubation & $100(49.5)$ & $30(14.9)$ & $72(35.6)$ & $<0.001$ \\
\hline Not to use nasogastric tube & $113(55.9)$ & $21(10.4)$ & $68(33.7)$ & $<0.001$ \\
\hline \multirow{2}{*}{$\begin{array}{l}\text { Repeated courses of antibiotics for infection } \\
\text { despite no improvement noted }\end{array}$} & $120(61.5)$ & $52(26.7)$ & $23(11.8)$ & 0.001 \\
\hline & & $\begin{array}{l}\text { Nasogastric tube (elder) - } \\
\text { small oral feeding } \\
\text { (next of kin) }\end{array}$ & $\begin{array}{l}\text { Small oral feeding (elder) - } \\
\text { nasogastric tube } \\
\text { (next of kin) }\end{array}$ & \\
\hline \multirow[t]{2}{*}{ Feeding preference in advanced dementia } & $164(82)$ & $12(6)$ & $24(12)$ & 0.065 \\
\hline & & $\begin{array}{l}\text { Non-invasive positive } \\
\text { pressure ventilation (elder) - } \\
\text { oral medications } \\
\text { (next of kin) }\end{array}$ & $\begin{array}{l}\text { Oral medications (elder) - } \\
\text { non-invasive positive } \\
\text { pressure ventilation } \\
\text { (next of kin) }\end{array}$ & \\
\hline Treatment preference in shortness of breath & $121(59.9)$ & $27(13.4)$ & $54(26.8)$ & 0.004 \\
\hline
\end{tabular}

intubation $(49.5 \%)$, and nasogastric tube feeding (55.9\%).The corresponding discordance in the paired samples of 'elder agreed / next of kin disagreed'were $33.7 \%, 35.6 \%$, and 33.7\%, respectively. Discordance between the paired samples was significant in terms of treatment preference in case of short of breath $(\mathrm{p}=0.004)$ and all end-of-life care preferences, except for'let nature guide one's life'.

\section{DISCUSSION}

In our study, $7.9 \%$ of elders preferred doctors to discuss advance care planning with family members only. This is in contrast to a study that reported $83 \%$ (15 of 18) of participants preferred their family members to make decisions, ${ }^{11}$ and another study that reported that non-critically ill Asian patients prefer to leave end-of-life decisions to their family members. ${ }^{15}$ In our study, elders and family members embraced an end-of-life discussion, although 'death and dying' has traditionally been a taboo in Chinese culture. It must be emphasised that end-of-life care planning focuses on 'living as much as possible' rather than 'dying'. The quality of end-of-life discussion affects the quality of the dying experience. Information exchange is an integral component of decision making. ${ }^{2}$ During the information exchange process, it is important to maintain a meaningful sense of hope while preparing both patients and family members for dying. ${ }^{2}$ In a study of determinants of family's agreement on achieving a good level of hope and preparing for a patient's death in Asian cancer patients and their relatives, the determinants were pacing the explanation according to the family's preparedness, discussing the patient's priorities while the patient was still well enough to participate, willingness to talk about concerns about alternative medicine, maximising the patient's physical ability for daily activities and independence, and setting specific and achievable goals. ${ }^{16}$

In the 2015 Quality of Death Index, among the 80 countries evaluated, Hong Kong ranked 22nd overall (5th in Asia) and 38th in terms of community engagement. Taiwan ranked sixth overall (1st in Asia). A Taiwan case study reported the importance of community engagement, in particular to break down cultural taboos against discussing death, initiation of changes via education, and introduction of life and death discussions in the education system from primary school to university.17 This aimed to shift the paradigm of filial duty and allow love to be 
expressed with the family member at the end of life, and encourage acceptance of disease and peaceful passing. ${ }^{17}$

In clinical practice in Hong Kong, common endof-life care options include CPR, artificial feeding, and invasive mechanical ventilation. In our study, $65.5 \%$ and $64.8 \%$ of the elders preferred not to use CPR and mechanical ventilation, respectively, whereas $74.9 \%$ preferred not to use artificial feeding. In a study of older people in aged homes, $61.4 \%$ of participants did not want life-sustaining treatments or devices and $74.0 \%$ would refuse artificial feeding. ${ }^{9}$ In a study of mostly community-living elders with chronic disease, in the event of a terminal illness, $80 \%$ and $81 \%$ did not want CPR or artificial ventilation, respectively, and $69 \%$ would refuse tube feeding. ${ }^{10}$ The percentage difference may be partly due to the setting of the interview and the in-patients of an acute medical unit of a regional teaching hospital. In a study of 18 older Chinese interviewed, 14 preferred not to have aggressive medical treatments to prolong life if they were terminally ill. ${ }^{11}$

In Hong Kong, it is common practice to ask family members to make surrogate decisions when the patient is in a critical condition or coma. In our study, there was significant discordance between the paired samples in most end-of-life care preferences including life-sustaining interventions or devices, artificial feeding, pain management, antibiotic use, and means to relieve shortness of breath in latestage COPD. Advance care planning can help the patient to clarify their own understanding of illness and treatment options; allow family members and healthcare professionals to understand the patient's values, beliefs, and goals of care; and identify the patient's wishes. It empowers patients to have a say about their current and future treatment. Advance care planning is a means by which to improve patient autonomy, even when he/she loses that capacity, and to assist family members and health care professionals in the provision of end-of-life care treatment in the patient's best interests. A recent systematic review of the consistency of end-of-life preferences over time suggested that patients who engaged in advance care planning or completed an advance directive have more consistent end-of-life preferences. ${ }^{18}$

In our study, older age was the predictor for the preference for not to use CPR. Higher number of acute admissions in the past year was the predictor for the preference against not to use CPR and nasogastric tube feeding and the preference against 'nature to guide one's life'. One possible explanation is that these elders had higher death anxiety and wanted to defer death. In our study, health status or the number of comorbidities was not associated with end-of-life care preferences. This is similarly reported in one study. ${ }^{19}$ Older individuals who had experience with end-of-life care of others demonstrated greater readiness to participate in advance care planning. ${ }^{19}$ Persons who had been hospitalised in the past year were more likely than their counterparts to engage in advance care planning. ${ }^{20}$

Our study has several limitations. The sample was not stratified and the sample size was small and not representative of the community-dwelling elders with medical problems. Self-rated life satisfaction was not based on a validated quality-of-life instrument. Participants' experience of life-sustaining treatment (eg, tube feeding or repeated course of antibiotics) was not examined; this may have affected their decisions about end-of-life care preferences.

\section{CONCLUSION}

There was significant discordance in end-of-life care preferences between elders and their next of kin. In order to deliver end-of-life care in accordance with elder's values and beliefs, advance care planning should be discussed with them before they become too ill to do so.

\section{ACKNOWLEDGMENTS}

This study was supported by the Hong Kong Geriatric Society. The authors thank all staff of the participating centres for assistance.

\section{REFERENCES}

1. Singer PA, Martin DK, Kelner M. Quality end-of-life care: patients' perspectives. JAMA 1999;281:163-8.

2. Myers J. Improving the quality of end-of-life discussions. Curr Opin Support Palliat Care 2015;9:72-6.

3. Detering KM, Hancock AD, Reade MC, Silvester W. The impact of advance care planning on end of life care in elderly patients: randomised controlled trial. BMJ 2010;340:c1345.

4. Bischoff KE, Sudore R, MiaoY, Boscardin WJ, Smith AK. Advance care planning and the quality of end-of-life care in older adults. J Am Geriatr Soc 2013;61:209-14.

5. Leung JM, Udris EM, Uman J, Au DH. The effect of end-of-life 
discussions on perceived quality of care and health status among patients with COPD. Chest 2012;142:128-33.

6. Brinkman-Stoppelenburg A, Rietjens JA, van der Heide A. The effects of advance care planning on end-of-life care: a systematic review. Palliat Med 2014;28:1000-25.

7. Chu WW, Leung AC, Chan KS, Wu YM, Leung DM. A breakthrough in the end-of-life care in a nursing home in Hong Kong. J Hong Kong Geriatr Soc 2002;11:38-41.

8. Chu WW, Woo J. Attitudes of Chinese elders towards advance planning on end-of-life issues: a qualitative study in a nursing home in Hong Kong. J Hong Kong Geriatr Soc 2004;12:18-23.

9. Chu LW, Luk JK, Hui E, et al. Advance directive and end-oflife care preferences among Chinese nursing home residents in Hong Kong. J Am Med Dir Assoc 2011;12:143-52.

10. Ting FH, Mok E. Advance directives and life-sustaining treatment: attitudes of Hong Kong Chinese elders with chronic disease. Hong Kong Med J 2011;17:105-11.

11. Ho SW, Sanders GF. Preferences on end-of-life decisions among older Chinese in Macau. J Transcult Nurs 2015;26:15763.

12. Katz S. Downs TD, Cash HR, Grotz RC. Progress in development of the index of ADL. Gerontologist 1970;10:20-30.

13. Hartigan I. A comparative review of the Katz ADL and the
Barthel Index in assessing the activities of daily living of older people. Int J Older People Nurs 2007;2:204-12.

14. Fung AW, Lam LC, Lui VW. Could hypothetical scenarios enhance understanding on decision for life-sustaining treatment in non-demented Chinese older persons? Aging Ment Health 2010;14:994-9.

15. Bowman KW, Singer PA. Chinese seniors' perspectives on endof-life discussions. Soc Sci Med 2001;53:455-64.

16. Shirado A, Morita T, Akazawa T, et al. Both maintaining hope and preparing for death: effects of physicians' and nurses' behaviors from bereaved family members' perspectives. J Pain Symptom Manage 2013;45:848-58.

17. The 2015 Quality of Death Index. Ranking palliative care across the world. A report by the Economist Intelligence Unit.

18. Auriemma CL, Nguyen CA, Bronheim R, et al. Stability of endof-life preferences: a systemic review of the evidence. JAMA Intern Med 2014;174:1085-92.

19. Amjad $\mathrm{H}$, TowleV, Fried T. Association of experience with illness and end-of-life care with advance care planning in older adults. J Am Geriatr Soc 2014;62:1304-9.

20. Carr D, Khodyakov D. End-of-life health care planning among young-old adults: an assessment of psychosocial influences. $J$ Gerontol B Psychol Soc Sci 2007;62;S135-41. 